\title{
Adult Conditional Knockout of PGC-1 $\alpha$ Leads to Loss of Dopamine Neurons
}

\author{
Haisong Jiang ${ }^{1,2,3,4 *}$, ${ }^{\circledR}$ Sung-Ung Kang ${ }^{1,2,3,4 *}$, Shuran Zhang, ${ }^{5}$ Senthilkumar Karuppagounder ${ }^{1,2,3,4}$, \\ Jinchong Xu, ${ }^{1,2}$ (1) Yong-Kyu Lee, ${ }^{1,2}$ B) Bong-Gu Kang, ${ }^{1,2}$ () Yunjong Lee ${ }^{1,6,3,4}$, (1) Jianmin Zhang, ${ }^{1,2}$ Olga \\ Pletnikova, ${ }^{7}$ Juan C. Troncoso, ${ }^{2,7}$ Shelia Pirooznia ${ }^{1,2,3,4}$, Shaida A. Andrabi, ${ }^{1,2}$ Valina L. \\ Dawson, ${ }^{1,2,3,4,5,6}$ and ${ }^{-}$Ted M. Dawson ${ }^{1,2,3,4,5,8}$
}

\section{DOI:http://dx.doi.org/10.1523/ENEURO.0183-16.2016}

\begin{abstract}
${ }^{1}$ Neuroregeneration and Stem Cell Programs, Institute for Cell Engineering, Johns Hopkins University School of Medicine, Baltimore, Maryland 21205, 2 Department of Neurology, Johns Hopkins University School of Medicine, Baltimore, Maryland 21205, ${ }^{3}$ Adrienne Helis Malvin Medical Research Foundation, New Orleans, Louisiana 701302685, ${ }^{4}$ Diana Helis Henry Medical Research Foundation, New Orleans, Louisiana 70130-2685, ${ }^{5}$ Solomon H. Snyder Department of Neuroscience, Johns Hopkins University School of Medicine, Baltimore, Maryland 21205, ${ }^{6}$ Department of Physiology, Johns Hopkins University School of Medicine, Baltimore, Maryland 21205, ${ }^{7}$ Division of

Neuropathology, Department of Pathology, Johns Hopkins University School of Medicine, Baltimore, Maryland 21205, and ${ }^{8}$ Department of Pharmacology and Molecular Sciences, Johns Hopkins University School of Medicine, Baltimore, Maryland 21205
\end{abstract}

\section{Visual Abstract}

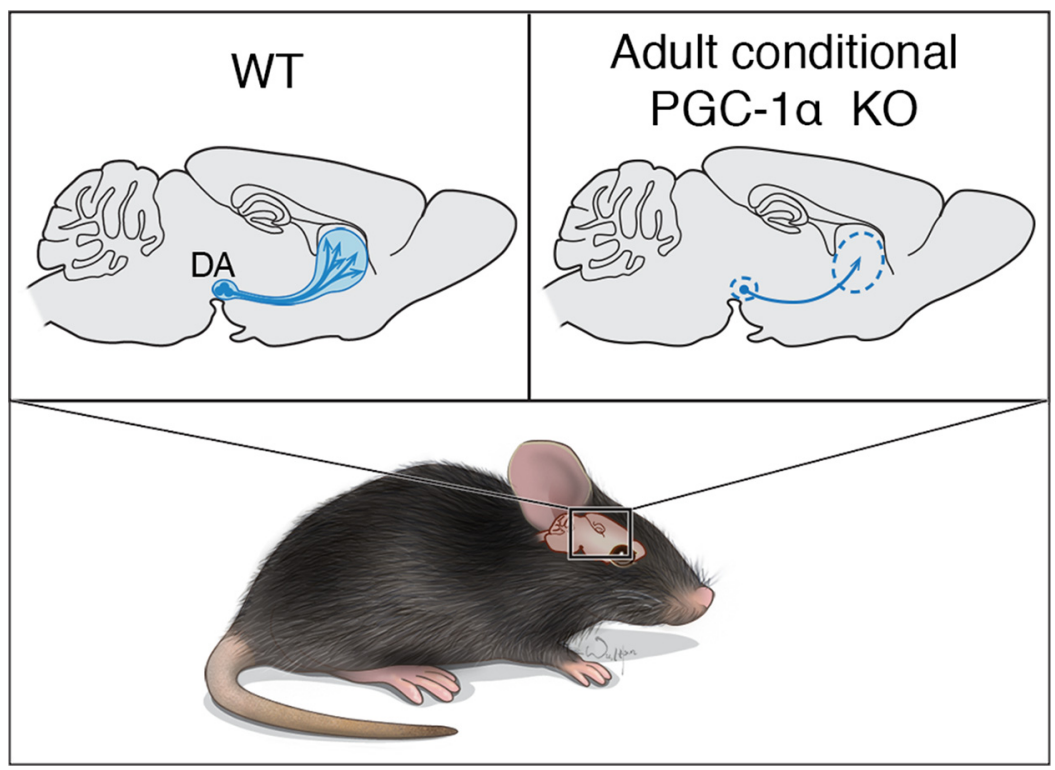

Parkinson's disease (PD) is a chronic progressive neurodegenerative disorder. Recent studies have implicated a role for peroxisome proliferator-activated receptor $\gamma$ coactivator protein-1 $\alpha$ (PGC-1 $\alpha)$ in PD and in animal or cellular models of PD. The role of PGC- $1 \alpha$ in the function and survival of substantia nigra pars compacta (SNpc) dopamine neurons is not clear. Here we find that there are four different PGC- $1 \alpha$ isoforms expressed in SH-SY5Y cells, and these four isoforms are expressed across subregions of mouse brain. Adult conditional PGC- $1 \alpha$ knock-out mice show a significant loss of dopaminergic neurons that is accompanied by a reduction of dopamine in the striatum. In human PD postmortem tissue from the SNpc, there is a reduction of PGC- $1 \alpha$ isoforms and mitochondria mark-

\section{Significance Statement}

Recent studies indicate a role for peroxisome proliferator-activated receptor $\gamma$ coactivator protein-1 $\alpha$ (PGC-1 $\alpha$ ) in maintaining dopaminergic function as well as in promoting survival against toxic environments when overexpressed. It is not yet known whether PGC- $1 \alpha$ is required for adult dopaminergic neuronal viability. To address this hypothesis, we investigated dopaminergic neuronal viability in mice following adult conditional knockout of PGC-1 $\alpha$ and found that the loss of PGC- $1 \alpha$ is sufficient to result in the loss of dopaminergic neurons. 
ers. Our findings suggest that all four isoforms of PGC- $1 \alpha$ are required for the proper expression of mitochondrial proteins in SNpc DA neurons and that PGC-1 $\alpha$ is essential for SNpc DA neuronal survival, possibly through the maintenance of mitochondrial function.

Key words: dopamine neuron; mitochondria; neurodegeneration; PGC-1 $\alpha$; substantia nigra

\section{Introduction}

Parkinson's disease (PD) is the second most common chronic progressive neurodegenerative disorder. As PD progresses, patients experience motor symptoms, including tremor, slowness of movement, stiffness, loss of balance, as well as nonmotor symptoms. The changes in motor function are due to the loss of dopaminergic (DA) neurons. The factors responsible for promoting DA neuronal viability and DA neuronal death are under investigation (Lee et al., 2012; Calabresi et al., 2013). Recently, a role for peroxisome proliferator-activated receptor $\gamma$ coactivator protein-1 $\alpha$ (PGC-1 $\alpha$ ), a transcriptional coactivator, has been implicated in DA neuronal function and viability. Well studied gene targets for PGC-1 $\alpha$ include those involved in energy metabolism, mitochondrial biogenesis, mitochondrial quality control, and mitochondrial function. Through single nucleotide polymorphism analysis, PGC- $1 \alpha$ and brain-specific isoforms of PGC- $1 \alpha$ have been implicated in neurodegenerative diseases, including amyotrophic lateral sclerosis, Huntington's disease, and Parkinson's disease (Soyal et al., 2012; Eschbach et al., 2013). In a genome-wide meta-analysis of gene expression from patients with PD and incipient Lewy body disease, genes regulated by PGC- $1 \alpha$ are downregulated (Zheng et al., 2010), and there are PGC- $1 \alpha$ polymorphisms that are risk factors for the development of PD

Received June 28, 2016; accepted August 10, 2016; First published August 16, 2016.

The authors declare no competing financial interests.

Author contributions: H.J., S.-U.K., V.L.D., and T.M.D. designed the research; H.J., S.-U.K., S.Z., S.K., J.X., Y.-K.L., B.-G.K., Y.L., J.Z., and S.A.A. performed research; O.P. and J.C.T. contributed unpublished reagents/analytic tools; H.J., S.-U.K., S.Z., S.K., J.X., Y.-K.L., B.-G.K., Y.L., J.Z., and S.A.A. analyzed data; H.J., S.-U.K., S.P., V.L.D., and T.M.D. wrote the paper.

This research was supported by National Institutes of Health/National Institute of Neurological Disorders and Stroke Grant NS038377, the JPB Foundation, the Adrienne Helis Malvin Medical Research Foundation, and the Diana Helis Henry Medical Research Foundation. T.M.D. is the Leonard and Madlyn Abramson Professor in Neurodegenerative Diseases.

${ }^{*}$ H.J. and S.-U.K. contributed equally to this work.

Y. Lee's present address: Division of Pharmacology, Department of Molecular Cell Biology, Sungkyunkwan University School of Medicine, Samsung Biomedical Research Institute, Suwon 440-746, South Korea.

J. Zhang's present address: Department of Immunology, Neuroscience Center, Institute of Basic Medical Sciences, Chinese Academy of Medical Sciences and School of Basic Medicine, Peking Union Medical College, State Key Laboratory of Medical Molecular Biology, Beijing 100005, People's Republic of China.

Correspondence should be addressed to either Valina L. Dawson or Ted M. Dawson, Neuroregeneration and Stem Cell Programs, Institute for Cell Engineering, Johns Hopkins University School of Medicine, 733 North Broadway, Suite 731, Baltimore, MD 21205, E-mail: vdawson@jhmi.edu or tdawson@jhmi.edu.

DOI:http://dx.doi.org/10.1523/ENEURO.0183-16.2016

Copyright (C) 2016 Jiang et al.

This is an open-access article distributed under the terms of the Creative Commons Attribution 4.0 International, which permits unrestricted use, distribution and reproduction in any medium provided that the original work is properly attributed.
(Clark et al., 2011). Additionally, in PD postmortem substantia nigra pars compacta (SNpc), there is epigenetic regulation by promoter-proximal cytosine methylation of the PPARGC1A gene, which encodes PGC- $1 \alpha$ and results in the reduced expression of PGC- $1 \alpha$ in cell models (Su et al., 2015). In murine primary cortical cultures, genetic deletion of PGC- $1 \alpha$ leads to small increases in oligomeric $\alpha$-synuclein, a key proteinaceous component of Lewy bodies, which is a hallmark feature of PD (Eschbach et al., 2015). In experimental models, PGC- $1 \alpha$ overexpression blocks dopaminergic cell loss caused by A53T $\alpha$-synuclein expression, rotenone intoxication, or parkin deficiency (Ebrahim et al., 2010). The absence of PGC-1 $\alpha$ leads to increased susceptibility to the PD neurotoxin 1-methyl-4-phenyl-1,2,3,6-tetrahydropyridine (MPTP; StPierre et al., 2006). In the setting of parkin gene deletion, the elevation of PARIS, a transcriptional corepressor of PGC- $1 \alpha$, leads to the repression of PGC- $1 \alpha$. Dopaminergic loss observed due to parkin deletion and PARIS expression can be reversed by the overexpression of PGC-1 $\alpha$ (Shin et al., 2011). Together, these studies indicate a pivotal role for of PGC- $1 \alpha$ in dopaminergic function and a contributory role in DA neuronal viability. However, it is unknown whether PGC- $1 \alpha$ is required for adult dopaminergic neuronal viability. To address this possibility, we investigated dopaminergic neuronal viability in mice following adult conditional knockout of PGC- $1 \alpha$. We report that the loss of PGC- $1 \alpha$ results in the loss of dopaminergic neurons.

\section{Materials and Methods}

\section{Animals}

All experimental protocols using animals were approved by the Johns Hopkins Institutional Animal Care and Use Committee. Conditional PGC- $1 \alpha$ knock-out mice were purchased from The Jackson Laboratory (https:// www.jax.org/strain/009666).

\section{Immunohistochemistry}

For immunohistochemistry, animals were perfused with PBS followed by $4 \%$ paraformaldehyde. Brains were postfixed with $4 \%$ paraformaldehyde and cryoprotected in $30 \%$ sucrose. Coronal sections, including striatum and ventral middle brain, were incubated with rabbit polyclonal anti-tyrosine hydroxylase (TH; catalog \#NB300109, Novus Biologicals; RRID: AB_350437). The image was visualized with 3,3'-diaminobenzidine (Sigma-Aldrich) and analyzed by Stereo Investigator software. The sections were incubated with goat polyclonal anti-green fluorescent protein (GFP) (catalog \#ab6673, Abcam; RRID: AB_305643), and secondary antibodies were coagulated with Alexa fluorescent for $1 \mathrm{~h}$ at room temperature. Brain cell lysates were immunoblotted with mouse mono antiPGC-1 $\alpha$ (catalog \#ST1202, Millipore; RRID: AB_2237237), rabbit polyclonal anti- succinate dehydrogenase complex, 
subunit A (SDHA; catalog \#5839S, Cell Signaling Technology; RRID:AB_10707493), mouse mono anti-Tomm20 (translocase of outer mitochondrial membrane 20; catalog \#WH0009804M1, Sigma-Aldrich; RRID:AB_1843992), monoclonal anti- $\beta$-actin-peroxidase (Sigma-Aldrich catalog \#A3854; RRID:AB_262011).

\section{HPLC}

Striatal tissue was dissected and sonicated in $0.2 \mathrm{ml}$ of ice-cold $0.01 \mathrm{~mm}$ perchloric acid containing $0.01 \%$ EDTA and $60 \mathrm{~nm}$ 3,4-dihydroxybenzylamine as an internal standard. After centrifugation, $20 \mu \mathrm{l}$ of the supernatant was injected into a column by using a Prostar-410 autosampler and isocratically eluted through a $4.6 \times 150 \mathrm{~mm} \mathrm{C}-18$ reverse-phase column. The mobile phase consisted of 90 $\mathrm{mm} \mathrm{NaH} \mathrm{PO}_{4}, 1.7 \mathrm{~mm}$ octane sulfonic acid, $50 \mu \mathrm{M}$, EDTA, and $10 \%$ acetonitrile, and the flow rate was kept at 0.9 $\mathrm{ml} / \mathrm{min}$. Biogenic amines and their metabolites were detected by a dual-channel Coulchem III electrochemical detector, and the cell potential was set at $\mathrm{E} 1$ of $-150 \mathrm{mV}$ and E2 of $+220 \mathrm{mV}$, and a guard cell at $+350 \mathrm{mV}$. Data were collected and processed using external standards for respective amines on Clarity data acquisition software. The protein concentrations of tissue homogenates were measured using the BCA Protein Assay kit. Data were normalized to protein concentrations and expressed in nanograms per milligram protein, as previously described (Karuppagounder et al., 2016).

\section{Stereotaxic intranigral virus injection}

For stereotaxic injection of rAAV1 overexpressing GFP or Cre-GFP, 12 6-week-old PGC-1 $\alpha^{\text {flox/flox }}$ mice of either sex were anesthetized with pentobarbital. An injection cannula was applied stereotaxically into the SNpc unilaterally, as previously described (Shin et al., 2011). The infusion was performed using a total of 1-2 $\mu \mathrm{l}$ of a hightiter adeno-associated virus (AAV)-GFP or AAV-Cre-GFP that was injected into each mouse. Mice were randomized for terminal analysis at 4 weeks or 6 months after injection. For Western blot analysis, SNpcs were dissected 4 weeks after viral injection, and protein samples were blotted with the primary antibodies.

\section{Amphetamine-induced stereotypic rotation}

Four weeks after mice received the AAV1-GFP or AAV1-Cre-GFP intranigral injection into the right hemisphere, $5 \mathrm{mg} / \mathrm{kg}$ amphetamine was intraperitoneally administered to mice (Lee et al., 2013). Mice were placed into a white paper cylinder of $20 \mathrm{~cm}$ diameter and recorded by video for $30 \mathrm{~min}$. For the last $10 \mathrm{~min}$, full-body ipsilateral rotations (clockwise) were counted in $1 \mathrm{~min}$ intervals by a blinded viewer.

\section{Primer sequences for reverse transcription-PCR}

The following primer sequences were used for reverse transcription (RT)-PCR: Exon B1: forward, TAC AAC TAC GGC TCC TCC TGG; Exon B2: forward, ATG GAT GAA GGG TAC TTT TGTG; Exon 3: reverse, TCA AAT GAG GGC AAT CCG TC; Exon 1: forward, TGA GTC TGT ATG GAG TGA CAT CGA GTG; mouse $\alpha 4$ : forward, TCA CAC CAA ACC CAC AGA AA; mouse $\alpha 4$ : reverse, CTG GAA
GAT ATG GCA CAT; Human $\alpha 4$ : forward, TCA CAC CAA ACC CAC AGA GA; Human $\alpha 4$ : reverse, CTG GAA GAT ATG GCA CAT; Mouse Tomm20: forward, TGC TCT AAT TCC CAA GTA CTG G; Mouse Tomm20: reverse, GCA TTT GAT CCT GTA AGC TGC; Mouse SDHA: forward, ACA TTC GAC AGG GGA ATG G; Mouse SDHA: reverse, CCA AAG TAA CCT TGC CAG TC; GAPDH: forward, TGG TCT CCT CTG ACT TCA ACA GCG; GAPDH, reverse, AGG GGT CTA CAT GGC AAC TGT GAG; Mouse GAPDH: forward, CTA CAC TGA GGA CCA GGT TGT C, reverse, GTT ATT ATG GGG GTC TGG GAT GG.

\section{Statistical analyses}

All quantitative data are expressed as the mean \pm SEM. Statistical significance was determined by Student's $t$ test. Respective $p$ values are indicated in the figure legends.

\section{Results}

Since studies suggest that there is significant compensation in the dopaminergic neuronal system when genes are deleted or overexpressed in the germline and thus during development of the dopaminergic system (Dawson et al., 2010; Shin et al., 2011), we chose to conditionally delete PGC- $1 \alpha$. To avoid potential developmental compensation, exons 3-5 of PGC- $1 \alpha$ were deleted in 6-weekold PGC-1 $\alpha^{\text {flox/flox }}$ mice (Lucas et al., 2012) by ventral midbrain stereotaxic injection of a GFP-fused Cre recombinase AAV (AAV-Cre-GFP). Ventral midbrain injection of AAV expressing GFP (AAV-GFP) in PGC- $1 \alpha^{\text {flox/flox mice }}$ served as a control (Fig. 1A). Four weeks after injection, effective transduction was assessed by GFP expression, which demonstrates robust colocalization with $\mathrm{TH}$ containing neurons within the substantia nigra (Fig. 1B). Transduction with AAV-CRE-GFP leads to a $78.0 \%$ loss of the PGC- $1 \alpha 1$ isoform and a $59.1 \%$ loss of the PGC- $1 \alpha 4$ isoform compared with the control AAV-GFP-injected mice (Fig. $1 C, D$ ). Immunoblot analysis also reveals the reduction of two additional isoforms of PGC- $1 \alpha-\mathrm{a} 100$ $\mathrm{kDa}$ isoform that is reduced by $54.9 \%$ and a $160 \mathrm{kDa}$ isoform that is reduced by $91.5 \%$ following AAV-CREGFP (Fig. 1C,D). The reduction in the 100 and $160 \mathrm{kDa}$ bands following conditional knockout of PGC- $1 \alpha$ suggests that the 100 and $160 \mathrm{kDa}$ bands represent unrecognized isoforms of PGC- $1 \alpha$ in the brain. Since PGC- $1 \alpha$ contributes to the regulation of mitochondrial biogenesis (Scarpulla, 2011), mitochondrial markers for biogenesis were assessed. Accompanying the loss of the PGC-1 $\alpha$ isoforms is a $52.5 \%$ reduction in mitochondrial protein SDHA and a $58.7 \%$ reduction in TOMM20 (Fig. 1C,D). Together, these data show that we achieved a conditional deletion of PGC- $1 \alpha$ accompanied by the loss of mitochondrial markers for biogenesis.

Our observations of the reduction in the additional 100 and $160 \mathrm{kDa}$ PGC- $1 \alpha$ bands following conditional deletion suggest that there may be unrecognized genomic complexity to PGC- $1 \alpha$ than previously thought. The genomic complexity of the protein-coding gene for PGC- $1 \alpha$ (Human-GRCh38/hg38; chr4:23,770,000-24,475,000 and Mouse-GRCm38/mm10; chr5:51,450,000-52,120,000) was revealed by cap analysis gene expression (CAGE) dataset from the FANTOM genomics consortium (phases 
A
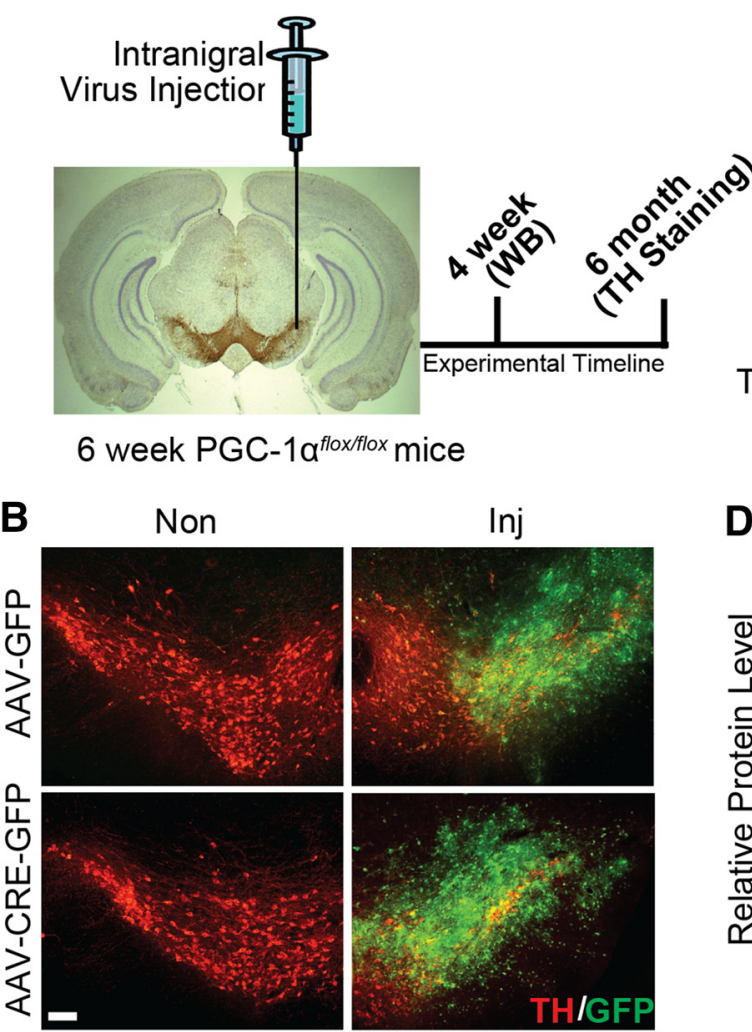

D

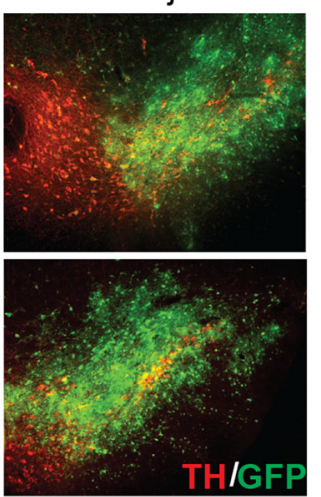

C
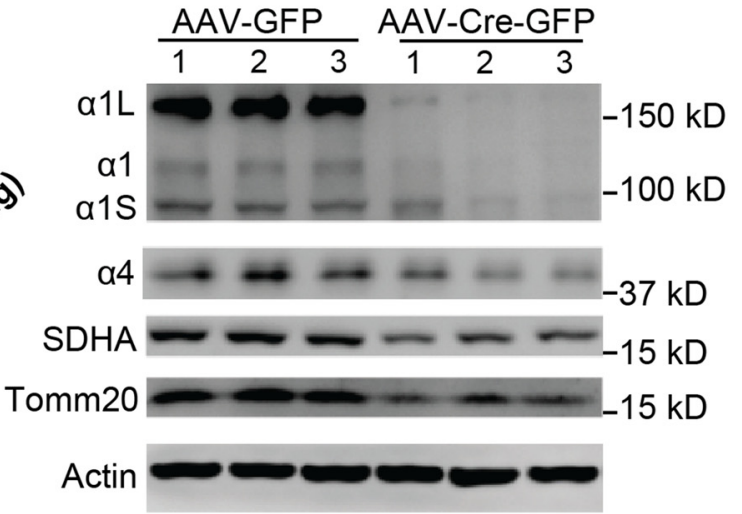

AAV-GFP AAV-Cre-GFP

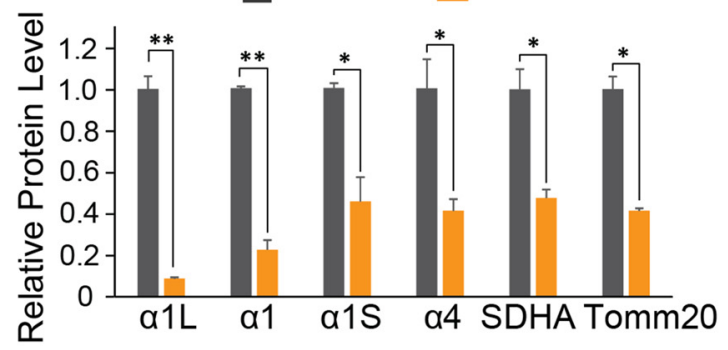

Figure 1. Adult conditional gene deletion of PGC-1 $\alpha$. $\boldsymbol{A}$, Experimental schematic of stereotaxic intranigral virus injection and experimental time line. $\boldsymbol{B}$, Representative GFP and TH-positive immunostaining of midbrain section from SNpc of PGC-1 $\alpha^{\text {flox/flox }}$ mice injected with AAV-GFP or AAV-Cre-GFP 6 months after the injection of virus. Scale Bar, $100 \mu \mathrm{m}$. C, Immunoblots of PGC-1 $\alpha$, SDHA, Tomm20, and $\beta$-actin 4 weeks after stereotactic delivery of AAV-GFP and AAV-Cre-GFP into PGC- $1 \alpha^{\text {flox } / \text { flox }}$ mice; $n=3 /$ group. $\boldsymbol{D}$, Quantification of $\boldsymbol{C}$ normalized to $\beta$-actin; $n=3$ /group. $* p<0.05, * * p<0.005$. Inj, Injected.

1-5) through hubs on the University of California, Santa Cruz (UCSC) Genome Browser (Brett et al., 2002; Forrest et al., 2014). Expressed sequence tags (ESTs) from humans and transcription start site (TSS) activity from mice coupled with the enhancer signal indicate that PGC- $1 \alpha$ is structurally dynamic in both humans and mice, and thus that there may be additional isoforms of PGC- $1 \alpha$ in addition to those previously investigated (Ruas et al., 2012; Fig. 2A). To determine whether the 100 and $160 \mathrm{kDa}$ bands that we observed are alternate PGC- $1 \alpha$ isoforms, we designed PCR primers for two of these alternative isoforms that are conserved between mouse and human to determine whether the message coding for these isoforms exists in mouse brain or mouse heart or the human SH-SY5Y neuroblastoma cell line. Two of these isoforms, which we designate PGC- $1 \alpha 1 \mathrm{~L}$ and PGC- $1 \alpha 1 \mathrm{~S}$ corresponding to their transcript size, are detected by RT-PCR (Fig. 2B). PGC- $1 \alpha 1$ and PGC- $1 \alpha 4$ are also detected in both mouse brain and heart and in SH-SY5Y cells (Fig. 2B). The PGC- $1 \alpha 1 \mathrm{~L}$ codes for a PGC- $1 \alpha$ isoform with a predicted molecular weight of $160 \mathrm{kDa}$ and the PGC$1 \alpha 1 S$ codes for a PGC- $1 \alpha$ isoform with a predicted molecular weight $100 \mathrm{kDa}$ are consistent with our immunoblot results. Corresponding to the reduction of PGC- $1 \alpha$ protein in the conditional knockout of PGC- $1 \alpha$, we ob- served an $83.0 \%$ decrease of PGC- $1 \alpha 1 \mathrm{~L}$ RNA, a $65.1 \%$ decrease of PGC- $1 \alpha 1$ RNA, a decrease of $48.6 \%$ PGC$1 \alpha 1$ S RNA, and a $56.7 \%$ decrease of PGC- $1 \alpha 4$ RNA in the conditional knockout of PGC-1 $\alpha$ (Fig. 2C,D). Accompanying the decrease of the RNA of PGC- $1 \alpha$ isoforms is a $51.7 \%$ reduction in SDHA RNA, and a $43.7 \%$ reduction in TOMM20 RNA (Fig. 2C,D).

To determine whether PGC- $1 \alpha$ is important in the survival of dopamine neurons, dopaminergic neuronal viability was assessed in the SNpc of adult conditional PGC-1 $\alpha$ knock-out mice. Conditional knockout of PGC- $1 \alpha$ leads to a $51.7 \%$ reduction in tyrosine hydroxylase-positive dopaminergic neuron and a $51.2 \%$ reduction in Nissl-stained neurons 6 months after stereotaxic injection of AAV-CREGFP into the ventral midbrain of PGC- $1 \alpha^{\text {flox/flox }}$ mice compared with the PGC- $1 \alpha^{\text {flox/flox }}$ mice injected with control AAV-GFP (Fig. 3A,B). Accompanying the loss of dopamine neurons is a $36.6 \%$ reduction in dopamine in the striatum, as determined by HPLC (Fig. $3 \mathrm{C}$ ) and a trend toward a reduction in the dopamine metabolites 3,4dihydroxyphenylacetic acid (DOPAC) and homovanillic acid (HVA; Fig. 3D). Since the AAV injection is unilateral, amphetamine-induced rotation was monitored to assess the functional loss of dopamine neurons. The AAV-Cre- 
A
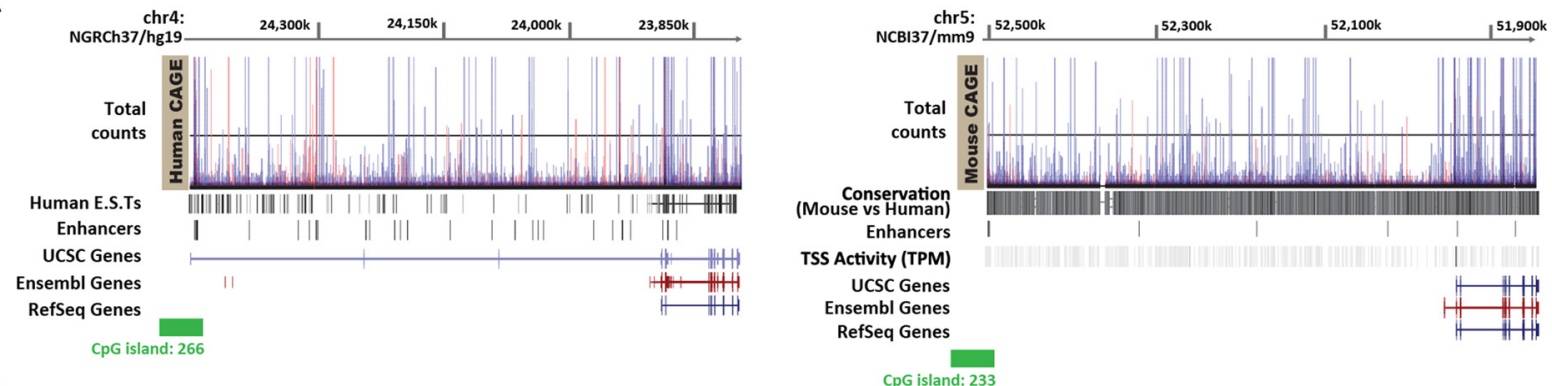

B

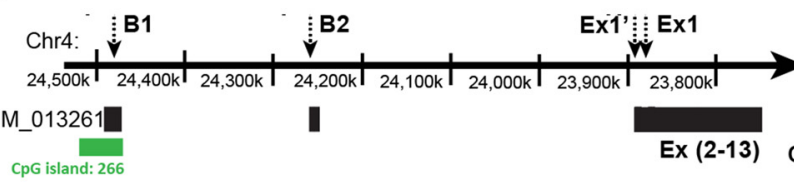

$\alpha 1 L$

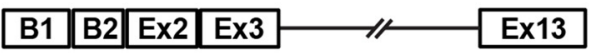

a1 Ex1 Ex2 Ex3

a1s

\begin{tabular}{|l|l|l|l|l|l|l|}
\hline$B 2$ & $E x 2$ & $E x 3$ & \\
\hline
\end{tabular}

a4

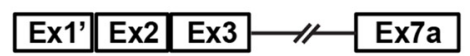

GAPDH
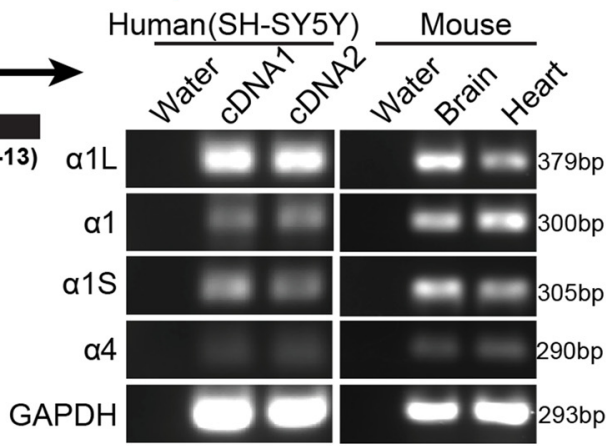

a1L"a1 $a 1 S \rrbracket \alpha 4$

C

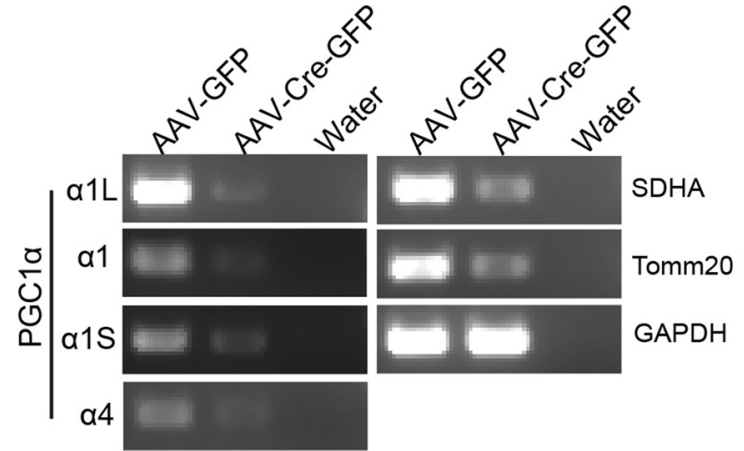

D

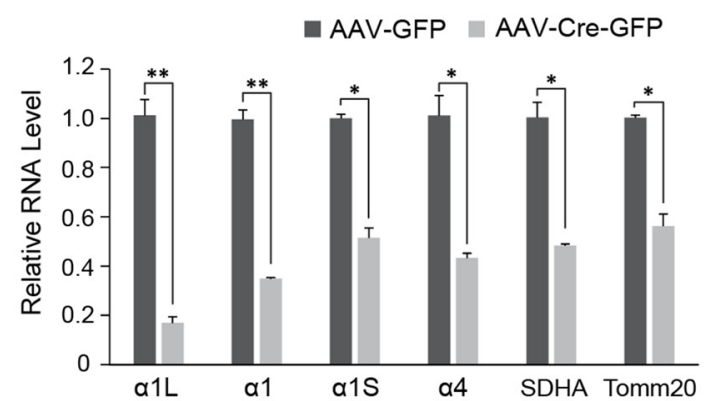

Figure 2. PGC- $1 \alpha$ isoforms. $\boldsymbol{A}$, The illustration of PGC- $1 \alpha$ new alternative exons and known exons in RefSeq/Ensembl/UCSC genome references. Human ESTs and mouse TSS with enhancer signals derived from $>1000$ human and mouse primary cells, cell lines, and tissues were mapped using CAGE. B, Diagram and PCR products show four different PGC-1 $\alpha$ isoforms from SH-SY5Y and mouse brain and heart. C, RT-PCR for four PGC- $1 \alpha$ isoforms, SDHA, Tomm20, and GAPDH RNA 4 weeks after stereotactic delivery of AAV-GFP or AAV-Cre-GFP into PGC- $1 \alpha^{\text {flox/flox }}$ mice; $n=3 /$ group. $\boldsymbol{D}$, Quantification of $\boldsymbol{C}$ normalized to GAPDH; $n=3 / g$ roup. $* p<$ $0.05, * * p<0.005$.

GFP-injected mice exhibit robust ipsilateral turning, while the AAV-GFP-injected mice do not rotate (Fig. 3E).

The levels of PGC- $1 \alpha$ isoforms were monitored in human postmortem substantia nigra from PD and control patients (Table 1, Fig. 4). The $160 \mathrm{kDa} P G C-1 \alpha$ isoform is reduced by $91.2 \%$. The PGC-1 $1 \alpha 1$ isoform was not detectable in human postmortem tissue. We cannot know whether this lack of detection is due to the specificity of the antibody or to the low abundance of this isoform coupled with the age of the tissue. The PGC- $1 \alpha 4$ isoform is reduced by $44.7 \%$. Accompanying these reductions in PGC- $1 \alpha$ isoforms is a reduction in the mitochondrial proteins associated with mitochondrial biogenesis by $49.3 \%$ in SDHA and a 61.3\% reduction in TOMM20 (Fig. 4A,B). Together, these data indicate that there is a reduction, in the human condition, in PGC-1 $\alpha$ expression that is reflected in the loss of markers associated with mitochon- drial biogenesis, suggesting that there is mitochondrial dysfunction in PD substantia nigra.

\section{Discussion}

The major finding of this study is the observation that adult conditional knockout of PGC- $1 \alpha$ isoforms leads to a loss of dopamine neurons in the substantia nigra. We also identify two brain-enriched isoforms of PGC- $1 \alpha$ that we denote PGC-1 $1 \alpha 1 \mathrm{~L}(160 \mathrm{kDa})$ and PGC-1 $\alpha 1 \mathrm{~S}$ (100 kDa). Importantly, these two isoforms are significantly reduced in human postmortem PD substantia nigra. Future studies will be required to understand the regulatory mechanisms of the alternative PGC- $1 \alpha$ isoforms identified here.

A potential role for PGC-1 $\alpha$ in PD was first suggested by the observation that germline deletion of PGC- $1 \alpha$ increased the susceptibility of mice to the neurotoxin MPTP, which is used to selectively produce DA neurotoxicity (St-Pierre et al., 2006). However, the absence of the 
A

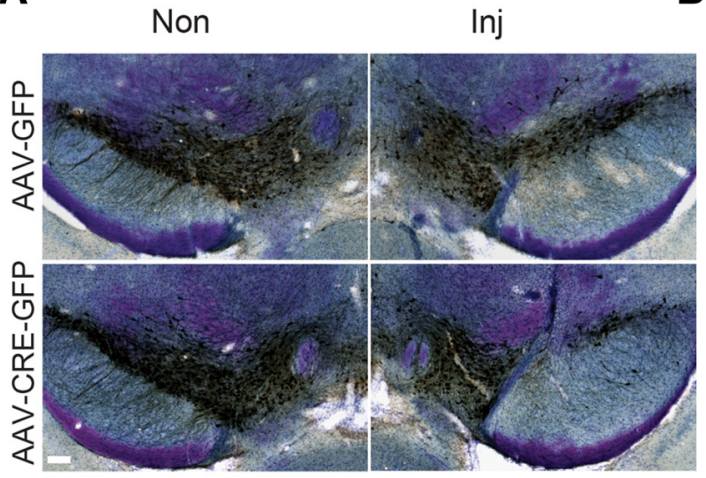

C

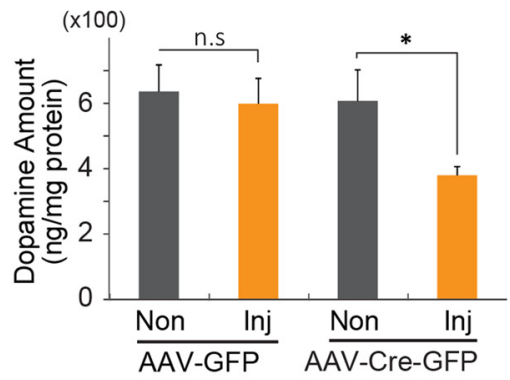

B

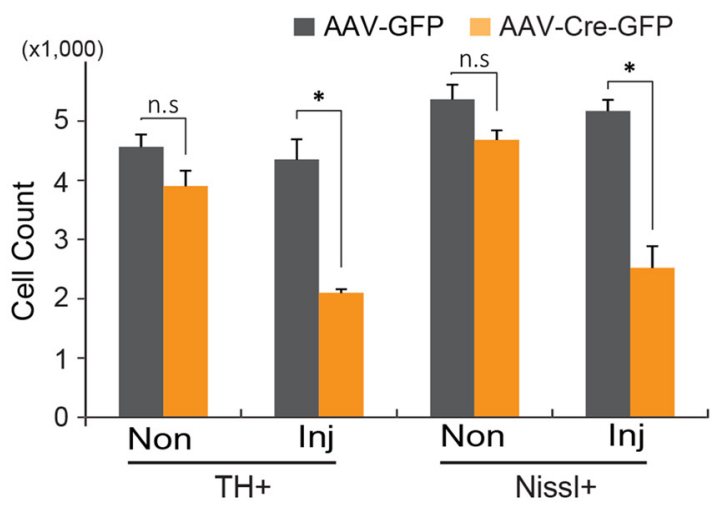

E

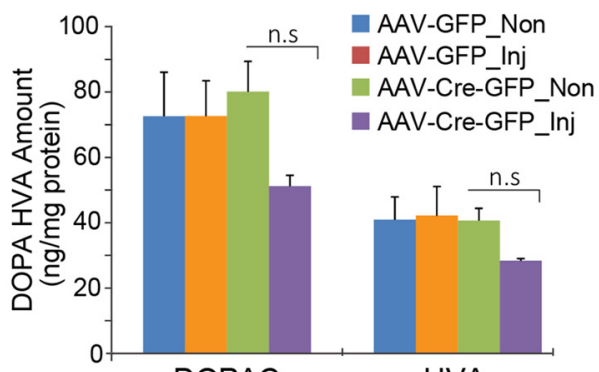

DOPAC

HVA

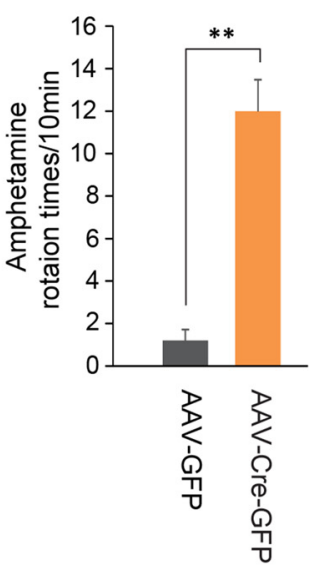

Figure 3. Gene deletion of PGC-1 $\alpha$ leads to the loss of dopamine neurons in the SNpc. A, Representative TH immunohistochemistry and Nissl staining of midbrain sections from SNpc of PGC- $1 \alpha^{\text {flox/flox }}$ mice injected with AAV-GFP or AAV-Cre-GFP 6 months after the injection of virus. Scale bar, $100 \mu \mathrm{m}$. B. Stereological assessment of TH- and Nissl-positive neurons in the SNpc of PGC-1 $\alpha^{\text {flox/flox }}$ mice injected with AAV-GFP or AAV-Cre-GFP ( $n=3$ /group). C, HPLC assessment of the striatal content of dopamine. $\boldsymbol{D}$, HPLC assessment of the striatal content of dopamine metabolites DOPAC and HVA. $\boldsymbol{E}$, Amphetamine-induced ipsilateral rotations $(n=$ 3/group). Data are expressed as the mean \pm SEM. $* p<0.05, * * p<0$. 005. Inj, Injected; n.s, not significant.

degeneration of dopamine neurons in the germline PGC- $1 \alpha$ knock-out mice suggested that PGC- $1 \alpha$ was not required for the survival of dopamine neurons. Moreover, the overexpression of PGC- $1 \alpha$ was shown to impair dopaminergic function and increase the susceptibility of dopamine neurons to MPTP (Ciron et al., 2012; Clark et al., 2012), raising the idea that PGC- $1 \alpha$ might be toxic to dopamine neurons. The notion that PGC- $1 \alpha$ was not

Table 1: Human postmortem tissue used for immunoblot analysis in Figure 4

\begin{tabular}{llllll}
\hline Final diagnosis & Age (years) & Sex & Race & PMD & Tissue \\
Control & 71 & M & A & 24 & SN \\
Control & 71 & M & W & 14 & SN \\
Control & 80 & F & W & 6 & SN \\
Control & 83 & M & W & 21 & SN \\
PD, PD with dementia & 76 & M & W & 29 & SN \\
PD & 72 & M & W & 15 & SN \\
PD + dementia & 81 & F & W & 13 & SN
\end{tabular}

F, Female; M, male; A, African American; W, white; SN, substantia nigra; PMD, post-mortem delay. required for the survival of dopamine neurons was challenged by the discovery of parkin interacting substrate (PARIS; Shin et al., 2011). Adult conditional knockout of parkin leads to a progressive loss of dopamine neurons that is dependent upon PARIS repression of PGC- $1 \alpha$ (Shin et al., 2011; Siddiqui et al., 2015, 2016; Stevens et al., 2015). PARIS selectively represses PGC- $1 \alpha$ in the substantia nigra, leading to the loss of dopamine neurons due to the absence or inactivation of parkin. Consistent with the notion that PGC- $1 \alpha$ plays a role in the loss of dopamine neurons due to parkin inactivation is the observation that the overexpression of PGC- $1 \alpha$ prevents the loss of dopamine neurons due to the absence of parkin or PARIS overexpression. Thus, the failure to observe the loss of dopamine neurons in the germline deletion of PGC-1 $\alpha$ is likely due to developmental compensation. Our observations of the detrimental effect of adult conditional knockout of PGC- $1 \alpha$ in dopamine neurons supports the idea that PGC- $1 \alpha$ is required for the survival of dopamine neurons (Mudò et al., 2012; Ciron et al., 2015).

The lack of degeneration of dopamine neurons following germline deletion of PGC- $1 \alpha$ is likely due to compensatory 
A

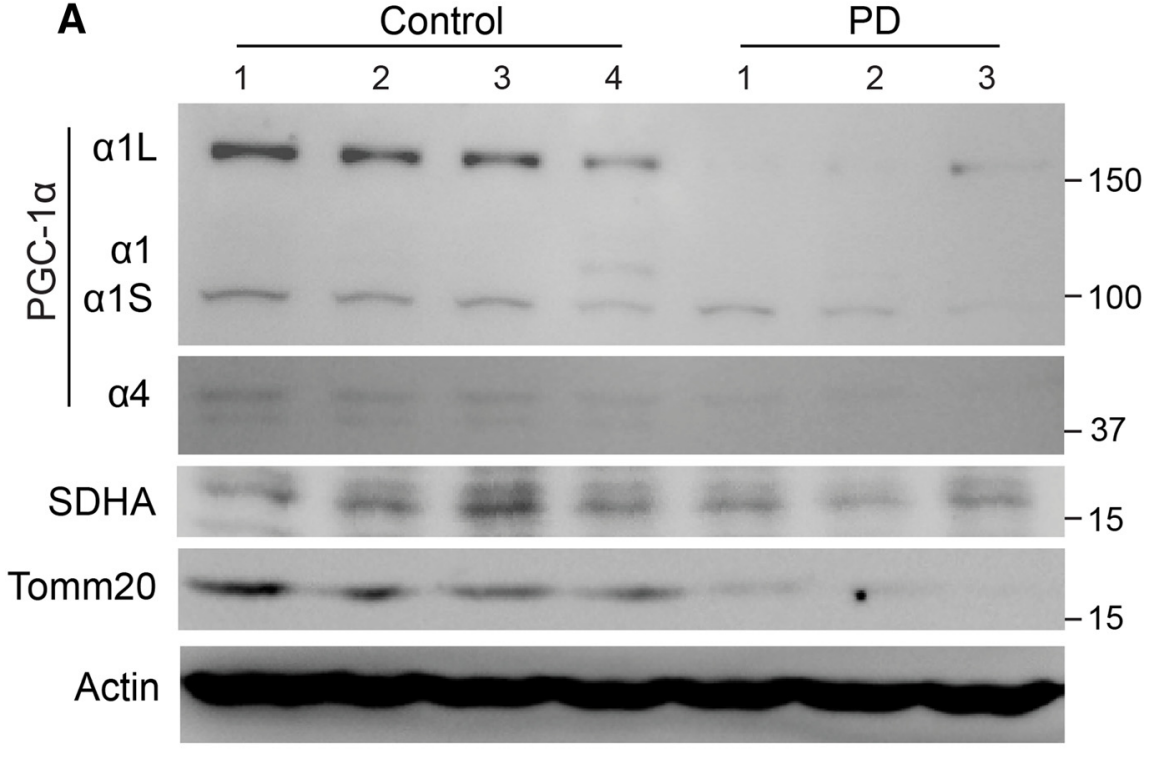

B

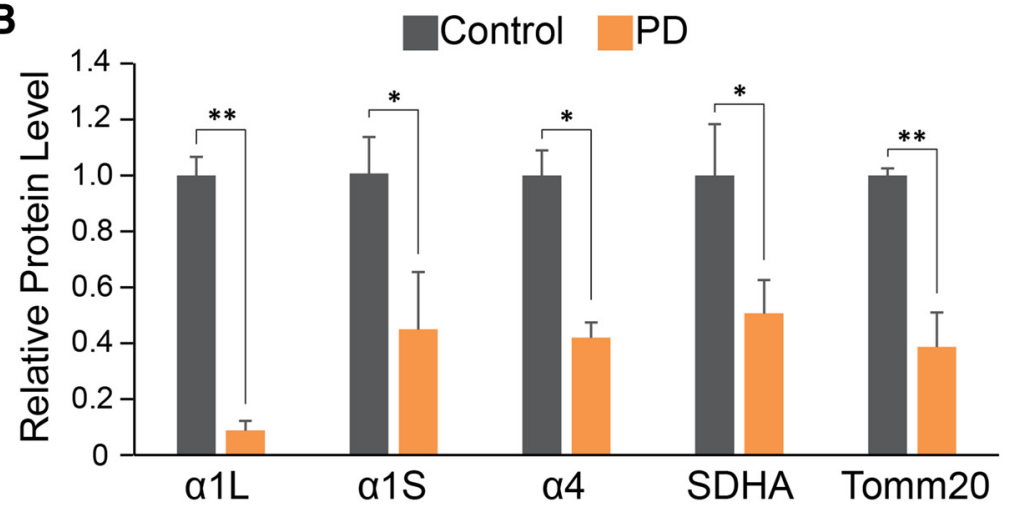

Figure 4. Reduction of PGC- $1 \alpha$ isoforms, SDHA, and Tomm20 in PD. $\boldsymbol{A}$, Immunoblots of PGC-1 $\alpha$, SDHA, Tomm20, and $\beta$-actin in SN of PD mouse compared with an age-matched control. $\boldsymbol{B}$, Quantitation of the immunoblots in $\boldsymbol{A}$ normalized to $\beta$-actin: Control, $n$ $=4$; PD mouse, $n=3$. $* p<0.05$, $* * p<0.005$.

mechanisms. It is well known that the rodent dopaminergic system possesses strong developmental compensatory mechanisms (Golden et al., 2013). For instance, the deletion of glial cell-derived neurotrophic factor (GDNF) during the critical period of dopamine neuronal development does not lead to the loss of dopamine neurons, whereas adult knockout of GDNF leads to a progressive loss of dopamine neurons (Granholm et al., 2011). In addition, germline deletion of parkin fails to lead to the loss of dopaminergic neurons, whereas adult conditional knockout of parkin leads to a progressive loss of dopamine neurons similar to the adult conditional knockout of PGC-1 $\alpha$ (Shin et al., 2011). Moreover, adult deletion of the LIM homeodomain transcription factors $L m \times 1 a$ and $L m \times 1 b$ leads to the loss of dopamine neurons (Doucet-Beaupré et al., 2016).

In sporadic PD, genes regulated by PGC- $1 \alpha$ are significantly reduced (Zheng et al., 2010; Shin et al., 2011). PGC- $1 \alpha$ regulates genes involved in mitochondrial respiration and mitochondrial antioxidant defense, as well as mitochondrial biogenesis (Dabrowska et al., 2015). Here, we observed a significant reduction in the levels of mitochondrial proteins involved in biogenesis, SDHA and TOMM20, suggesting that the reduction in PGC- $1 \alpha$ levels leads to a reduction in mitochondrial biogenesis. Similar observations have recently been reported in adult conditional parkin knock-out mice and mice overexpressing PARIS due to the reduction of PGC- $1 \alpha$ levels (Stevens et al., 2015). Together, these studies indicate that the maintenance of PGC- $1 \alpha$ levels in PD could offer neuroprotective therapeutic opportunities in PD (Zheng et al., 2010; Clark et al., 2011; Shin et al., 2011; Eschbach et al., 2015; Su et al., 2015).

Acknowledgments: We thank Dr. Joohoo Shin for helpful comments. We also thank the Adrienne Helis Malvin Medical Research Foundation and the Diana Helis Henry Medical Research Foundation for their joint participation through their direct engagement in the continuous active conduct of medical research in conjunction with The Johns Hopkins University Hospital and the Johns Hopkins University School of Medicine and the Parkinson's Disease Program. 


\section{References}

Brett D, Pospisil H, Valcárcel J, Reich J, Bork P (2002) Alternative splicing and genome complexity. Nat Genet 30:29-30. CrossRef Medline

Calabresi P, Di Filippo M, Gallina A, Wang Y, Stankowski JN, Picconi B, Dawson VL, Dawson TM (2013) New synaptic and molecular targets for neuroprotection in Parkinson's disease. Mov Disord 28:51-60. CrossRef Medline

Ciron C, Lengacher S, Dusonchet J, Aebischer P, Schneider BL (2012) Sustained expression of PGC-1 $\alpha$ in the rat nigrostriatal system selectively impairs dopaminergic function. Hum Mol Genet 21:1861-1876. CrossRef Medline

Ciron C, Zheng L, Bobela W, Knott GW, Leone TC, Kelly DP, Schneider BL (2015) PGC-1 $\alpha$ activity in nigral dopamine neurons determines vulnerability to $\alpha$-synuclein. Acta Neuropathol Commun 3:16. CrossRef Medline

Clark J, Reddy S, Zheng K, Betensky RA, Simon DK (2011) Association of PGC-1alpha polymorphisms with age of onset and risk of Parkinson's disease. BMC Med Genet 12:69 CrossRef Medline

Clark J, Silvaggi JM, Kiselak T, Zheng K, Clore EL, Dai Y, Bass CE, Simon DK (2012) Pgc-1 $\alpha$ overexpression downregulates Pitx 3 and increases susceptibility to MPTP toxicity associated with decreased Bdnf. PLoS One 7:e48925. CrossRef Medline

Dabrowska A, Venero JL, Iwasawa R, Hankir MK, Rahman S, Boobis A, Hajji N (2015) PGC-1 $\alpha$ controls mitochondrial biogenesis and dynamics in lead-induced neurotoxicity. Aging (Albany NY) 7:629647. CrossRef Medline

Dawson TM, Ko HS, Dawson VL (2010) Genetic animal models of Parkinson's disease. Neuron 66:646-661. CrossRef Medline

Doucet-Beaupré H, Gilbert C, Profes MS, Chabrat A, Pacelli C, Giguère N, Rioux V, Charest J, Deng Q, Laguna A, Ericson J, Perlmann T, Ang SL, Cicchetti F, Parent M, Trudeau LE, Lévesque $M(2016) \mathrm{Lmx1a}$ and $\mathrm{Lmx} 1 \mathrm{~b}$ regulate mitochondrial functions and survival of adult midbrain dopaminergic neurons. Proc Natl Acad Sci U S A 113:E4387-E4396. CrossRef Medline

Ebrahim AS, Ko LW, Yen SH (2010) Reduced expression of peroxisome-proliferator activated receptor gamma coactivator1 alpha enhances alpha-synuclein oligomerization and down regulates AKT/GSK3beta signaling pathway in human neuronal cells that inducibly express alpha-synuclein. Neurosci Lett 473:120125. CrossRef Medline

Eschbach J, Schwalenstocker B, Soyal SM, Bayer H, Wiesner D, Akimoto C, Nilsson AC, Birve A, Meyer T, Dupuis L, Danzer KM, Andersen PM, Witting A, Ludolph AC, Patsch W, Weydt P (2013) PGC-1 $\alpha$ is a malespecific disease modifier of human and experimental amyotrophic lateral sclerosis. Hum Mol Genet 22:3477-3484. CrossRef

Eschbach J, von Einem B, Muller K, Bayer H, Scheffold A, Morrison BE, Rudolph KL, Thal DR, Witting A, Weydt P, Otto M, Fauler M, Liss B, McLean PJ, Spada AR, Ludolph AC, Weishaupt JH, Danzer KM (2015) Mutual exacerbation of peroxisome proliferatoractivated receptor $\gamma$ coactivator $1 \alpha$ deregulation and $\alpha$-synuclein oligomerization. Ann Neurol 77:15-32. CrossRef Medline

Forrest AR, Kawaji H, Rehli M, Baillie JK, de Hoon MJ, Haberle V, Lassmann T, Kulakovskiy IV, Lizio M, Itoh M, Andersson R, Mungall CJ, Meehan TF, Schmeier S, Bertin N, Jørgensen M, Dimont E, Arner E, Schmidl C, Schaefer U, et al. (2014) A promoter-level mammalian expression atlas. Nature 507:462-470.

Golden JP, Demaro JA 3rd, Knoten A, Hoshi M, Pehek E, Johnson EM Jr, Gereau RW 4th, Jain S (2013) Dopamine-dependent compensation maintains motor behavior in mice with developmental ablation of dopaminergic neurons. J Neurosci 33:17095-17107. CrossRef

Granholm AC, Zaman V, Godbee J, Smith M, Ramadan R, Umphlet C, Randall P, Bhat NR, Rohrer B, Middaugh LD, Boger HA (2011) Prenatal LPS increases inflammation in the substantia nigra of Gdnf heterozygous mice. Brain Pathol 21:330-348. CrossRef Medline

Karuppagounder SS, Xiong Y, Lee Y, Lawless MC, Kim D, Nordquist E, Martin I, Ge P, Brahmachari S, Jhaldiyal A, Kumar M, Andrabi
SA, Dawson TM, Dawson VL (2016) LRRK2 G2019S transgenic mice display increased susceptibility to 1-methyl-4-phenyl1,2,3,6-tetrahydropyridine (MPTP)-mediated neurotoxicity. J Chem Neuroanat . Advance online publication. Retrieved August 19, 2016. CrossRef

Lee Y, Dawson VL, Dawson TM (2012) Animal models of Parkinson's disease: vertebrate genetics. Cold Spring Harb Perspect Med. Advance online publication. Retrieved August 19, 2016. doi: 10.1101/cshperspect.a009324. CrossRef Medline

Lee Y, Karuppagounder SS, Shin JH, Lee YI, Ko HS, Swing D, Jiang H, Kang SU, Lee BD, Kang HC, Kim D, Tessarollo L, Dawson VL, Dawson TM (2013) Parthanatos mediates AIMP2-activated agedependent dopaminergic neuronal loss. Nat Neurosci 16:13921400. CrossRef Medline

Lucas EK, Dougherty SE, McMeekin LJ, Trinh AT, Reid CS, Cowell RM (2012) Developmental alterations in motor coordination and medium spiny neuron markers in mice lacking pgc-1alpha. PLoS One 7:e42878

Mudò G, Mäkelä J, Di Liberto V, Tselykh TV, Olivieri M, Piepponen P, Eriksson O, Mälkiä A, Bonomo A, Kairisalo M, Aguirre JA, Korhonen L, Belluardo N, Lindholm D (2012) Transgenic expression and activation of PGC-1 $\alpha$ protect dopaminergic neurons in the MPTP mouse model of Parkinson's disease. Cell Mol Life Sci 69:1153-1165. CrossRef Medline

Ruas JL, White JP, Rao RR, Kleiner S, Brannan KT, Harrison BC, Greene NP, Wu J, Estall JL, Irving BA, Lanza IR, Rasbach KA, Okutsu M, Nair KS, Yan Z, Leinwand LA, Spiegelman BM (2012) A PGC-1 $\alpha$ isoform induced by resistance training regulates skeletal muscle hypertrophy. Cell 151:1319-1331. CrossRef Medline

Scarpulla RC (2011) Metabolic control of mitochondrial biogenesis through the PGC-1 family regulatory network. Biochim Biophys Acta 1813:1269-1278. CrossRef Medline

Shin JH, Ko HS, Kang H, Lee Y, Lee YI, Pletinkova O, Troconso JC, Dawson VL, Dawson TM (2011) PARIS (ZNF746) repression of PGC-1alpha contributes to neurodegeneration in Parkinson's disease. Cell 144:689-702.

Siddiqui A, Bhaumik D, Chinta SJ, Rane A, Rajagopalan S, Lieu CA, Lithgow GJ, Andersen JK (2015) Mitochondrial quality control via the PGC1 $\alpha$-TFEB signaling pathway is compromised by Parkin Q311X mutation but independently restored by rapamycin. J Neurosci 35:12833-12844. CrossRef Medline

Siddiqui A, Rane A, Rajagopalan S, Chinta SJ, Andersen JK (2016) Detrimental effects of oxidative losses in parkin activity in a model of sporadic Parkinson's disease are attenuated by restoration of PGC1alpha. Neurobiol Dis 93:115-120. CrossRef

Soyal SM, Felder TK, Auer S, Hahne P, Oberkofler H, Witting A, Paulmichl M, Landwehrmeyer GB, Weydt P, Patsch W (2012) A greatly extended PPARGC1A genomic locus encodes several new brain-specific isoforms and influences Huntington disease age of onset. Hum Mol Genet 21:3461-3473. CrossRef Medline

St-Pierre J, Drori S, Uldry M, Silvaggi JM, Rhee J, Jäger S, Handschin C, Zheng K, Lin J, Yang W, Simon DK, Bachoo R, Spiegelman BM (2006) Suppression of reactive oxygen species and neurodegeneration by the PGC-1 transcriptional coactivators. Cell 127:397-408. CrossRef Medline

Stevens DA, Lee Y, Kang HC, Lee BD, Lee YI, Bower A, Jiang $\mathrm{H}$, Kang SU, Andrabi SA, Dawson VL, Shin JH, Dawson TM (2015) Parkin loss leads to PARIS-dependent declines in mitochondrial mass and respiration. Proc Natl Acad Sci U S A 112:11696-11701. CrossRef Medline

Su X, Chu Y, Kordower JH, Li B, Cao H, Huang L, Nishida M, Song L, Wang D, Federoff HJ (2015) PGC-1 $\alpha$ promoter methylation in Parkinson's disease. PLoS One 10:e0134087. CrossRef Medline

Zheng B, Liao Z, Locascio JJ, Lesniak KA, Roderick SS, Watt ML, Eklund AC, Zhang-James Y, Kim PD, Hauser MA, Grünblatt E, Moran LB, Mandel SA, Riederer P, Miller RM, Federoff HJ, Wüllner U, Papapetropoulos S, Youdim MB, Cantuti-Castelvetri I, et al. (2010) PGC-1alpha, a potential therapeutic target for early intervention in Parkinson's disease. Sci Transl Med 2:52ra73. 